\title{
The use of numerical models as a modern tool in fire investigation
}

\author{
Marius Cornel Șuvar ${ }^{1 *}$, Laurențiu Munteanu ${ }^{1}$ and Aurelian Nicola ${ }^{2}$ \\ ${ }^{1}$ National Institute for Research and Development in Mine Safety and Protection to Explosion - \\ INSEMEX Petroșani, 32-34 G-ral. Vasile Milea Street, Petroșani, 332047, Romania \\ ${ }^{2}$ University of Petroșani, 20 Universității Street, Petroșani, 332006, Romania
}

\begin{abstract}
Investigating the fire type events is characterized by a high degree of complexity, due to the fact that it has to find answers to aspects coming from multidisciplinary fields: technical-scientific, legal, organizational, psychological, etc. The management of the findings, the analyzed samples, and the resulting data implies a series of complex activities, based on the use of advanced procedures and techniques.

Fire investigation aims to determine the source of ignition and all the components that contribute to define the cause of the fire, to assess the motivations of the involved persons and to decipher the mechanism of heat transfer or burning processes that describes the propagation and development of a fire.

Often, in order to understand the mechanism of the pyrogenic phenomenon, the following approaches are used in the current practice: technical-scientific expertises, reconstruction of the event on the field or in the laboratory, sample analysis, and, last but not least, computer simulations.

This paper aims to highlight the role of the numerical models used in the field of fire safety, respectively in the elaboration of the post-event, technical-scientific expertises, by presenting some results obtained from the computer simulations, used to substantiate the fire mechanism and to formulate the conclusions.
\end{abstract}

\section{Introduction}

The investigation of a fire event's causes is a complex activity, implying that members of the investigative team have extensive knowledge about burning of materials, fire thermodynamics, experience, observation, analytical capacity, objectivity, visual and auditory memory.

It can be defined as a set of organizational, technical and operative measures and actions, based on specific methods, approaches and means, used in order to precisely establish the sources of initiation, the means of ignition, the circumstances, and, in certain cases, the responsible persons who generated or influenced the event.

Although at European level there is a tendency to standardize forensic investigations by conducting research by inspection bodies according to SR EN ISO / IEC 17020 standard,

\footnotetext{
* Corresponding author: marius.suvar@insemex.ro
} 
currently there is no unitary approach in the member states to legal regulations on fire investigation [1].

In Romania, investigation and determination of fire causes is carried out by criminal investigation bodies, in accordance with the law. The forensic investigation activity is led by the Forensic Service within the Criminal Investigation Section of the General Prosecutor's Office, attached to the High Court of Cassation and Justice. At the level of the prosecutor's offices attached to the courts of appeal and the county courts, there are criminalistic offices with tasks in the field of supervision and conducting of their own criminal investigation, as well as generalization of the latest technical-scientific method and means in the criminal investigation activity [1].

Where fire causes cannot be determined directly, due to factors such as special or unclear technical reasons, the magnitude of the event, the need for laboratory tests and technical-scientific expertise, or at the request of the criminal investigation authorities or other people involved, it is necessary to investigate the probable causes of fire $[2,3]$.

INCD-INSEMEX Petrosani, as a specialized institute for research and development and national authority, is empowered to perform technical expertises on events generated by explosions under GD no. 1461 / 18.10.2006 on the establishment, organization and functioning of the National Institute for Research and Development for Mine Safety and Protection to Explosion - INSEMEX Petrosani, having as object of activity "the development of methods for technical expertise of events caused by explosive and / or toxic atmospheres and or "explosive materials", "technical advice and assistance to the bodies responsible for the investigation of events" and "technical expertise for damages produced in the national economy".

The ability to study fire behavior by modern, numerical methods is not exactly new, the first attempts dating back to the early years of computing. Fundamental conservation equations governing fluid dynamics, heat transfer and combustion processes have been established more than a century ago. However, practical mathematical models designed to describe the behavior and evolution of fire have appeared relatively recently due to the inherent complexity of the problem. H.C. Hottel stated in 1984: "A case can be made for the fires, next to the life processes, the most complex of phenomena to be understood" [4].

This article highlights the role of using mathematical models, computer modeling and simulation of fire scenarios in the process of elaborating scientific and technical expertise to determine the causes and source of initiation of these events with undesirable consequences.

\section{Materials and methods}

\subsection{General considerations regarding the multidisciplinary research of fire causes and consequences}

The research of fire causes and consequences involves solving mainly the issues related to:

- Determination of the fire location (location of the initial fire / source of initiation);

- Determining the source of ignition, means that generated the fire, the combustible materials involved and the circumstances that led to the initiation of combustion, as well as the time at which the fire started;

- Determining the fire development mechanism, the post-initiation propagation manner and the factors that favored its evolution / regression;

- Identifying the circumstances and the role / culpability of the involved persons.

The research of fire event causes involves the following activities [2]:

- Investigation of the area/location of the fire; 
- Identification, discovery, classification and collection of eloquent evidences or material samples;

- Hearing eyewitnesses and other persons who may have data on the situation in the fireaffected objective or issues related to the event under investigation;

- Requesting the support of other authorized bodies with whom they cooperate in obtaining the data and information necessary to solve the case;

- Developing hypotheses and versions regarding the location, cause, and circumstances triggering the event;

- The necessity, in the case of complex situations, of laboratory tests in accredited laboratories or conducting experimental modeling and computerized simulations that can provide results that can confirm/invalidate hypotheses and explain ignition and fire development mechanism from the scientific, physicochemical point of view (technicalscientific expertise);

- Verification of different versions and hypotheses, formulation of conclusions.

The research process involves linking the following elements [1 - 3]:

- Technical data regarding the layout plan and characteristics of the building, room or technological installation where the event occurred, as well as data of the installations and utilities in operation (electrical, heating, ventilation, etc.);

- The technological processes/activities that took place in the affected object, the placing and condition of the machinery, their operating parameters;

- Information about the objects in the location prior to the fire initiation, their characteristics, their quantity, their fuel character, the state they were in and how they were arranged;

- The duties and tasks of each staff category in connection with the activities of the target on fire;

- The phase of activity in which the sections of the target were located (during/outside the work program);

- The fire evolution in time and space, the way of manifestation and the characteristic phenomena accompanying it (proportions in different phases, propagation velocity, intensity and duration of burning, main ignition place, appearance of flames, smoke, possible smells, noises, explosions, etc.);

- Information regarding fire detection and alarming, witnesses' issues, mobile and alarm time, alarming firemen and forensic experts,

- The meteorological situation during the pre-fire and during the fire;

- The manner in which the fire-fighting intervention took place, from the moment of its observation until its liquidation.

\subsection{Numerical methods used for fire modeling}

A model is an approach to use quantitative information in order to mathematically describe how the physico-chemical processes involved by fire mechanism will evolve over time, under specific conditions. The equations used to describe the flame amplitude or the movement of the air masses are simple algebraic equations. The more complex fire models use multiple differential equations, which are solved simultaneously using numerical methods. These require the use of a computer as well as the ability of the operator to accurately describe the structure of the modeled space and its characteristics through a three-dimensional network (mesh) [5]. Fire models were not initially designed to be used in fire investigation. They have been developed by fire protection specialists, initially due to the advantage of avoiding the need for physical experimentation and the support of data collected in fire tests. 
Equations describing mass, momentum and energy transport for fluid flows induced by combustion are to be simplified so that they can be effectively resolved for the studied fire scenarios. The general equations specific to fluid dynamics describe a wide variety of physical processes, many of which have nothing to do with the combustion process. In order to adapt these equations to the low-velocity movement of the gases, induced by the chemical release of heat or by the buoyancy forces, simplified equations were adopted, developed by Rheim and Baum, referred as low Mach burning equations. Equations with small Mach number are solved numerically by dividing the physical space in which the fire develops in a large number of rectangular cells. Within each cell, gas velocity, temperature, etc. are considered to be uniformly distributed, as they only evolve over time. The accuracy with which the dynamics of fire can be simulated depends on the number of cells considered in the model, this number depending largely and being limited by the available processing power $[5,6]$.

According to scientific literature [5, 7], there are two main approaches to numerical fire analysis. Each of these approaches treats fire inherently as a three-dimensional process that evolves over time. Zone models describe fire phenomena that occur in enclosed spaces (rooms, offices, buildings, etc.). Each compartment is divided into two homogeneous space volumes, a top layer, characterized by hot gases and a lower layer containing fresh air at lower temperatures. The conservation of masses and energies applies to each volume, along with additional models describing other physical processes defined by differential or algebraic equations, as appropriate. The most complete approach is field models, which solve numerically the $3 \mathrm{D}$ governing equations for a fire-driven flow in their differential form with varied levels of complexity.

Due to the fact that numerical models represent approximations of the physical phenomenon, there may often be limitations and constraints, which reduce their applicability. This consideration leads to the need to validate the model for each particular analyzed scenario.

\subsection{FDS - Fire Dynamic Simulator}

The fire field model - Fire Dynamics Simulator (FDS) is one of the most popular numerical model used for fire investigation. Based on Large Eddy Simulation (LES) approach for turbulence along with coupled combustion and radiation models, FDS represents an Open Source software package developed on the basis of partnership between various public and private organizations around the world, with the financial support of the National Institute of Standards and Technology (NIST) and VTT Technical Research Center of Finland. The FDS code is based on a modified form of the Navier-Stokes equations adapted to low-speed fluid flow due to temperature differences, while at the same time highlighting the spread of smoke and hot gases and heat transport as combustion products. Partial derivatives of conservation equations (mass, momentum and energy) are approximated as finite differences, and the solution is continually updated over a threedimensional mesh network.

FDS models use a mixture fraction model to simulate the combustion of fuel. Simplified, the mixture fraction model assumes a reaction of the following form:

$$
\begin{aligned}
& C_{x} \mathrm{H}_{y} \mathrm{O}=\mathrm{N}_{v} \mathrm{Other}_{w}+v_{\mathrm{O}_{2}} \mathrm{O}_{2} \rightarrow v_{\mathrm{CO}_{2}} \mathrm{CO}_{2}+v_{\mathrm{H}_{2} \mathrm{O}} \mathrm{H}_{2} \mathrm{O}+v_{\mathrm{CO}} \mathrm{CO}+v_{\text {soot }} \text { soot }+ \\
& v_{\mathrm{N}_{2}} \mathrm{~N}_{2}+v_{\mathrm{H}_{2}} \mathrm{H}_{2}+v_{\text {other }} \text { other }
\end{aligned}
$$

When the mixture fraction is between the lower and upper fuel-specific flammability limit, the combustion will take place regardless of if an ignition source is present or not. 
This will increase the generated heat from the combustion and, as a result, also increasing the temperatures.

The main advantage of this method is that it gives spatial variation and temporal evolution of the fire parameters, and visual information about the complex fire development. Disadvantage consists in the need for significant computing capabilities and familiarization with the application of the code [5].

\section{Results and discussions}

The FDS software package has been designed, since its conception, to solve practical problems involving the presence of fire in the engineering field of fire protection. At the same time, FDS is a particularly useful tool in the fundamental study of fire dynamics and combustion processes. Using specific techniques, these models can simulate phenomena such as heat and combustion products, radiation and convective heat transfer between gases and solid surfaces, the fire behavior and optimal activation mode of fire safety devices (sprinklers, heat detectors, smoke sensors, etc.). Complex phenomena can be studied at an advanced level: pyrolysis, fire development and its evolution in intensity, possibilities of fire suppression by using water extinguishing systems $[8,9]$.

The research of fire events focuses on two main directions: providing an effective tool to prevent the recurrence of these events and to offer well-argued information and methods to improve prevention activities and fire extinction techniques.

Studying the literature, we may observe that fire dynamics theories are currently used more in the preventative and investigative areas than in the operational area of fire service activities. However, in recent years, there is a growing interest in the use of FDS in the theoretical and practical training of firefighters [10,11], or as a support for fire safety specialists, with the purpose of initial design or improving the way the buildings and the fire protection systems reacts in fire emergency cases [12].

In order to demonstrate the analysis possibilities offered by the use of numerical models in the field of fire safety, respectively in the activity of post-event technical-scientific expertise elaboration, we will present below some computerized simulations for complex fire scenarios, made by INCD INSEMEX.

Figure 1 shows the virtual model of a residential building with its annexes (summer kitchen, warehouses, garages, various storage areas for firewood and animal feed, kennels). Within the technical expertise of the fire produced in the winter of 2017, the computerized simulations carried out led to the establishment of the ignition source of the event. Based on the available documentary material, based on the results obtained after the laboratory expertise of the material samples, correlation of fire effects with the fingerprint of the event and the witness statements, the next two plausible causes were retained for analysis, as sources of initiation of the event: Arson effect - the willful destruction of wood depot and of the kennels, or the existence of an electrical nature ignition source - a fault in the electrical distribution panel.

Following the computer simulations and the correlation of the event's footprint with the analyzed data, it was established that the event represented a generalized fire of the construction ensemble, with multiple initial outbreaks, identified at the wood depot and the animal annex attic, having, with high probability, the Arson effect as source of ignition.

The computerized analysis of the fire produced in the buildings ensemble for the studied case, required a mesh network with cells of $20 \times 20 \times 20 \mathrm{~cm}$ in size, for a good approximation and visualization of the dynamics of the fire, resulting in a number of 3,240,000 cells for the defined computational domain.

Due to the large computation volume demanded by the dimensions of the burned buildings ensemble and its interior components, the computational domain was 
subsequently segmented into 36 sub-domains (meshes) in order to reduce the simulation time, by running in parallel on several computational systems (computers), respectively in order to run several experiments, on various stages of fire development.

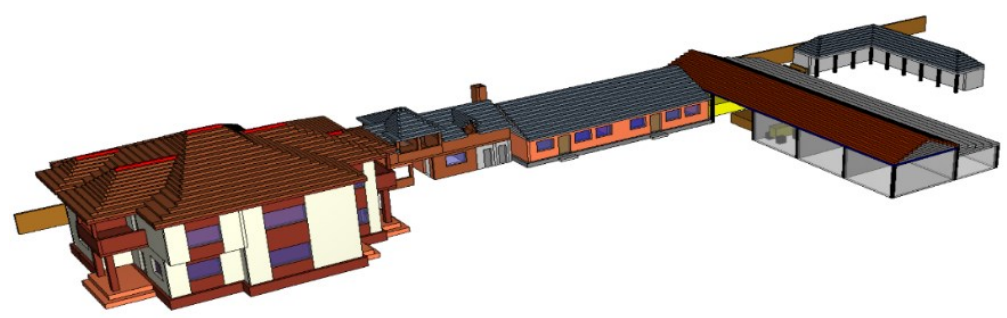

a)
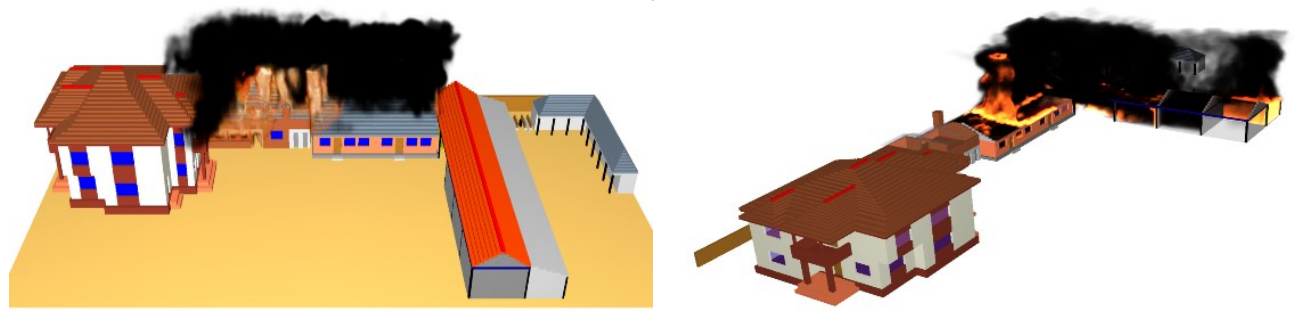

b)

Fig. 1. Virtual model for the analyzed case (a) and the fire evolution in the two different fire scenarios, used to determine the most probable ignition source (b)

Figure 2 shows the evolution of a fire event that took place at a school. The event had as a consequence the total destruction of two buildings, respectively the significant damage of the third building of the school. The event produced in 2018 was generated by a fire, most likely initiated by the improper functioning of the rectangular exterior lamp, located under the roofing board area of the access door in the school $\mathrm{C}$ building. The mentioned electrical consumer had a malfunction, most likely because of the decrease of the insulation resistance of the internal electrical circuits.
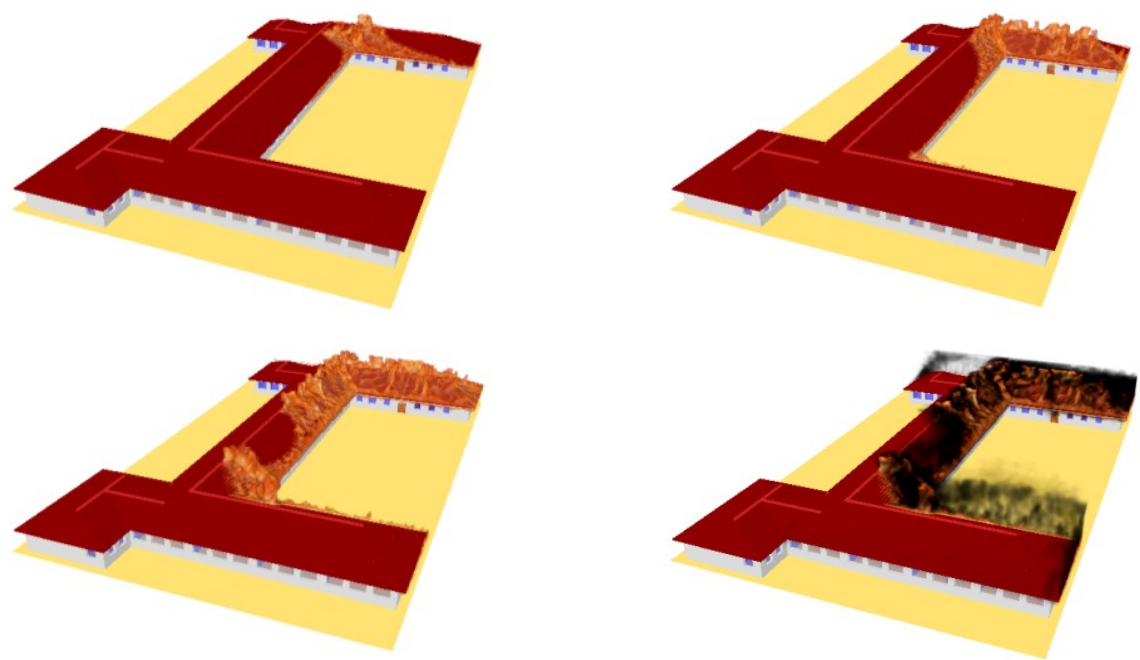

Fig. 2. Fire development and propagation at the roof level, and then, to the other buildings of the school (C, B and A) 
The information provided by fire simulations, along with visualization of the fire evolution in time, on the virtual model, showed a good correlation with the video sequences captured by surveillance cameras located both inside and outside the building complex. In this way, it was possible to establish the causes of the event occurrence, to identify the source of ignition and the favoring factors as well as to develop the fire mechanism.

The computer simulation for the fire produced at the mentioned school roof required a mesh with a cell's size of $20 \times 20 \times 20 \mathrm{~cm}$, for a good approximation and visualization of the fire dynamics, resulting in a number of 4,747,500 cells for the defined computational domain. This large computational domain demanded by the dimensions of the affected building and its interior components required subsequently segmentation into 32 subdomains in order to reduce the simulation time, by running in parallel on several computational systems (computers), respectively in order to run several experiments, on individual stages of fire.

\section{Conclusions}

The virtual reconstruction of the space where the fire took place helps the investigators to more precisely identify the behavior of this type of undesired event. Computerized simulation of the fire scenario using CFD (Computational Fluid Dynamic) techniques can provide new insights into investigating these phenomena. These simulations can reproduce the geometry of the site, reconstruct the combustion process, explain its development and illustrate the motion of the hot gases and smoke. Moreover, they can describe the characteristics of the combustible materials, the effect of ventilation or the impact of manual/automatic fire extinguishing systems.

By comparing the results obtained from the simulations with the conclusions drawn by the technical expertise of the real scenario, we can obtain additional evidence that more accurately describes the evolution of the combustion phenomenon and the migration of smoke and resulting gaseous products.

This paper was developed within the Nucleu Programme, carried out with the support of the Ministry of Research and Innovation - MCI, project no. PN 19-21-01-02.

\section{References}

1. S. Calotă, G. Popa, G. Sorescu, S. Dolha, Practical research guide of fire causes - $2 d n E d$. (in Romanian, Ed. Universul Juridic, București, 2016)

2. F. Stanciu, D.T. Toma, Particularity of fire and explosion research (in Romanian, Ed. Focus, București, 2005)

3. J. J. Lentini, Scientific Protocols for Fire Investigation (CRC Press, Taylor\& Francis, 2006)

4. H.C. Hottel, Combust Sci Technol., 39, 1-10 (1984)

5. K. McGrattan, S. Hostikka, J. Floyd, Fire dynamics simulator (Sixth Edition) User guide, (NIST Special Publication, 1019-6, 2019)

6. G. D. Florea, N. I. Vlasin, Z. Vass, B. A. Șimon, L. I. Tuhuț, Proceedings of International Multidisciplinary Symposium "Universitaria Simpro 2018" -8th Edition, 145-150 (2018)

7. G. Rein, A. Bar-Ilan, A. C. Fernandez-Pello, N. Alvarez, J of Fire Protection Engineering 16(3), 183-209 (2006)

8. B.M. Storm, M.R. Pantesjo, The use of simulation in fire investigation - Bachelor of Science Thesys (2009)

9. A.C.Y. Yuen, G.H. Yeoh, B. Alexander, M. Cook, Build. Simul. 7(5), 477-487 (2014)

10. O. Susan, Gh. Lazaroiu, V. Panaitescu, Proceedings of 6th International Conference on Management of Technological Changes, (1), 729-732 (2009) 
11. C. Popa, Gh. Lazaroiu, O. Susan, A. Chisacof, V. Panaitescu, Proceedings of the 5th Balkan Region Conference on Engineering and Business Education/2nd International Conferemce on Engineering and Business Education (I, II), 620-625 (2009)

12. C. Popa, Gh. Lazaroiu, I. Anghel, C. Petcana, Proceedings of 6th International Conference on Management of Technological Changes, (1), 691-694 (2009) 